(Thames marshes) or even good arable land, it is expensive and difficult to justify commercially; on the other hand, the waterside location, ease of excavation for docks, wharves, etc., and the possibility of building up the land by dredging silt from neighbouring watercourses and thus improving the river channels, makes this cheap land attractive to heavy industry. There is every reason to encourage industry to use such land; for example, Tees-side, Teesmouth, Thames-side, banks of Lower Medway, certain parts of Southampton Water, etc.

\title{
National Nutrition Policies
}

\section{By Sir John Boyd Orr, F.R.S.}

$I^{\mathrm{T}}$ $T$ has been known for many years that faulty diet is the direct cause of a heavy mortality throughout the world through deficiency diseases such as pellagra and beriberi, and, even in the wealthiest countries, of a great deal of ill-health. It has also been known that diseases due to faulty diet are possibly the easiest of all to prevent. Yet we are only now beginning to make a survey of the extent of the damage being done to the human race by malnutrition, and of our food resources available to prevent that damage.

Through the action of the League of Nations, this is now being done on an international basis*. Following the recommendation of the League's Mixed Committee on Nutrition, twenty-one countries have set up national nutrition committees to collect information regarding the state of nutrition in the different countries and to ascertain what is needed to make national dietaries fully adequate for health. The committees are conducting inquiries on what foods and what amounts of each are consumed by people of all classes and living under all sorts of conditions. This information, got by family budget inquiries and dietary surveys, enables estimates to be made of the nutritive value of the diet of different classes and also gives an indication of the level of income necessary for adequate nutrition. A parallel investigation of the state of nutrition of the families whose diets are determined will give some indication of the extent to which ill-health and poor physique can be attributed to deficiencies in the diet.

It is difficult, however, to assess the relative influence on health of faulty diet and of other factors inimical to health which usually accompany faulty diet. Useful information on this can be obtained by feeding experiments on children on poor diets, the deficiencies of which are made good by the addition of supplements of high nutritive value, and comparing the subsequent health of these children with that of children on similar diets and under comparable conditions but not receiving supplementary feeding. A further line of inquiry

* League of Nations. Survey of National Nutrition Policies, 1937-38. (Official No.: C478.M.321.1938.IIA.) Pp. 120. (Geneva: League of Nations; London: George Allen and Unwin, Ltd., 1938.) 2s. 6d. recommended is a survey of total national food supplies, home products plus imports, and a comparison of total food available with total national nutritional requirements. The information obtained in all these investigations will show what changes are needed in national food policies in the interest of health.

Governments were requested to furnish to the League annual reports on the work of their nutrition committees and the secretariat was instructed to publish an annual summary of these statements and of the proceedings of meetings of the representatives of the national committees. This survey of national nutrition policies now available gives the first annual report on the statements received and of the proceedings of the first meeting held last October, at which sixteen countries were represented.

Though the work of most of these committees is still in the initial stage, this report promises well for the success of the difficult work which they have undertaken. The information brought out in the preliminary inquiries shows the great need for a world-wide investigation and the immense possibilities of promoting human welfare by the application of "the newer knowledge of nutrition". The facts already revealed are sufficiently startling to warrant immediate changes in national food policies. Even in a country like Australia, where the standard of living is high compared with European countries, it was found that clinical survey with modern scientific methods revealed a quite unexpected amount of malnutrition. Of more than three thousand children examined in four inland areas, 17.9 per cent were recorded as showing evidence of unsatisfactory nutrition. An inquiry among pre-school children in Melbourne revealed evidence of malnutrition in 21.7 per cent of those examined. It is suggested that the malnutrition is due to a lack of dairy products, fruit and vegetables. The Australian Government has been trying to find a market for the export of these. It looks as if she has a market within her own borders which could be exploited to the great benefit of the people of Australia. In the United States, more than 60 per cent of the diets of Negro 
families in the south were found to be in need of improvement. In Hungary it was found that if requirements are to be fully met and exports maintained at the present level, milk production would need to be increased by 120 per cent and eggs by 470 per cent. In Jugoslavia, the peasant's winter diet consists almost solely of bread and beans. In summer, it provides nearly all the necessary elements, with the result that, in the autumn, there is a noticeable improvement in nutrition. Under the existing economic conditions, the peasant is obliged to sell his milk and eggs, and farm workers and children suffer from all kinds of deficiency diseases. Rickets and pellagra are specially common. During the Easter fast, epidemics of night-blindness and other eye diseases occur in certain regions. It is stated that some villages observe practically all orthodox fasts, which may amount to as many as 206 in the year.

These are examples of the kind of facts being brought to light by the work of these national nutrition committees. They are dealing with an urgent world-wide problem. They are showing the direction in which modern science can be most easily applied for the promotion of human welfare, pro- vided Governments can devise ways and means to increase production of the 'protective' foods, to facilitate distribution and adjust the economic system to bring a diet adequate for health within the reach of all and, at the same time, carry on educational campaigns so that families may be able to adjust their expenditure on food to the best advantage.

The work which the League of Nations has done in initiating and carrying on this work for the improvement of nutrition on an international basis is sufficient alone to justify its establishment. The League provides an international organization which can mass the world's scientific knowledge on the problem, and bring together the representatives of all the different countries once a year to get the mutual benefit of the exchange of information and the discussion of difficulties. The enthusiasm for the work would be increased with the knowledge that the information obtained is being used for the evolution of agricultural, trade and economic policies, designed to adjust national food supplies to national requirements and so bring the work of the national committees to full fruition.

\section{Element 43}

\section{By Prof. E. Segrè}

$\mathrm{E}$ VERY time that physics has offered a new analytical tool to chemistry, the most striking success has been the discovery of new elements. Rubidium and cæsium are thus offsprings of the use of the spectroscope, polonium and radium were discovered through the new methods of radioactivity, hafnium and rhenium were recognized through their X-ray spectra.

Mendeléeff's work, on the other hand, by classifying the chemical types, has in a way set a limit to the possibility of further discoveries and gives also a method of predicting rather exactly the properties of the missing elements. These are element 43, a lighter homologue of rhenium; element 61 , a rare earth ; element 87 , a halogen ; and element 89, an alkali. The search for these elements in the minerals, the only source at our disposal until a few years ago, has not been successful, and none of them seems to have been recognized with certainty in the earth's crust, in spite of considerable effort ${ }^{1}$.

Artificial radioactivity has supplied chemistry with a powerful new instrument, and from the point of view of the discovery of new elements its most striking feature is that one is able now to create, by transmutation from other elements, the element one wants to study. The first achieve- ment in this type of investigation was the discovery of transuranic elements by Fermi and his co-workers, continuing the periodic system above uranium (No. 92), although, in view of recent work, confirmation of their existence is needed.

In the search for the four missing elements lower than uranium, we have now been able to prepare element 43 and study its properties in detail. The substance was produced in the Berkeley cyclotron, which thus remains for the time being the only 'mine' of the element. It was made by bombarding molybdenum with deuterons or with neutrons ${ }^{2}$.

At least five radioactive isotopes of atomic number 43 have been recognized $z$ among the products of the bombardment, and some of them have a half-life long enough to permit a rather complete investigation of the chemical behaviour of element 43. Actually perusal of the periodic table may help to predict many of its chemical properties but, on the other hand, the finer details, often very important from the analytical point of view, may be found only by direct experiment.

The first properties to be studied obviously should be the analytical ones, in order to be able to identify the new element and separate it from all the others. Many of the separations are quite 